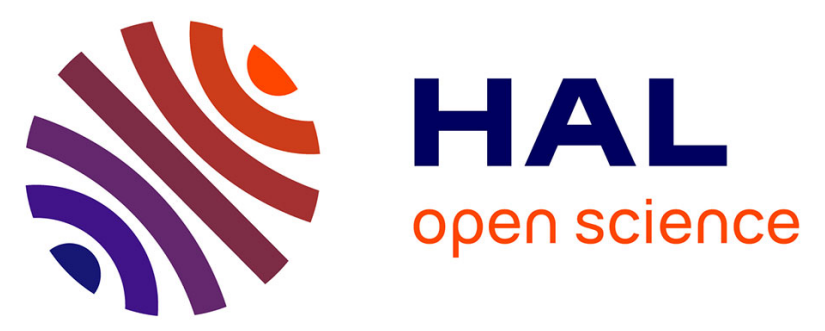

\title{
Study of Rice Identification during Early Season Using Multi-polarization TerraSAR-X Data
}

Lin Guo, Zhiyuan Pei, Shangjie Ma, Juanying Sun, Jiali Shang

\section{To cite this version:}

Lin Guo, Zhiyuan Pei, Shangjie Ma, Juanying Sun, Jiali Shang. Study of Rice Identification during Early Season Using Multi-polarization TerraSAR-X Data. 7th International Conference on Computer and Computing Technologies in Agriculture (CCTA), Sep 2013, Beijing, China. pp.337-347, 10.1007/978-3-642-54344-9_40 . hal-01220936

\section{HAL Id: hal-01220936 \\ https://hal.inria.fr/hal-01220936}

Submitted on 27 Oct 2015

HAL is a multi-disciplinary open access archive for the deposit and dissemination of scientific research documents, whether they are published or not. The documents may come from teaching and research institutions in France or abroad, or from public or private research centers.
L'archive ouverte pluridisciplinaire HAL, est destinée au dépôt et à la diffusion de documents scientifiques de niveau recherche, publiés ou non, émanant des établissements d'enseignement et de recherche français ou étrangers, des laboratoires publics ou privés. 


\title{
Study of Rice Identification during Early Season using Multi-polarization TerraSAR-X Data
}

\author{
Lin Guo $^{1, \mathrm{a}}$, Zhiyuan Pei ${ }^{1, \mathrm{~b}}$, Shangjie Ma ${ }^{1, \mathrm{c}}$, Juanying Sun ${ }^{1, \mathrm{~d}}$, Jiali Shang ${ }^{2, \mathrm{e}}$ \\ ${ }^{1}$ Chinese Academy of Agricultural Engineering, Ministry of Agriculture of China, Beijing, \\ 100105, China; \\ 2 Research Branch, Agriculture and Agri-Food Canada, Ottawa, Ontario K1A-0C6, Canada \\ aguo_guolin@126.com, ${ }^{\mathrm{b}}$ peizhiyuan@tom.com, ${ }^{\mathrm{c}}$ mashangjie@agri.gov.cn, \\ ${ }^{\mathrm{d}}$ sunjuanying_my@126.com, ${ }^{\mathrm{e}}$ shangj@agr.gc.ca
}

\begin{abstract}
The study of rice identification during early season aims to maintain cultivated area and distribution status of rice during its early season so as to provide decision support for agricultural management sectors to develop policies and measures, as well as important information for agricultural insurance sectors and agricultural products market. Multi-polarization TerraSAR-X data of Xuwen study site locating in Southern China were programmed during early season of early rice in the year of 2009. By means of comparing analysis, it is discovered that rice has more obvious identification features in jointing period and flowering period. Rice identification experiments are carried out using decision tree and object-oriented classification method. The results show that imagery acquired at the jointing period is more suitable for rice identification during the early season for a nationwide operational rice monitoring system.
\end{abstract}

Keywords: rice identification; early season; TerraSAR-X;

\section{Introduction}

Rice has the highest production and acreage of all grain crops in China. Most of China's paddy rice production is located in the southern provinces of the country where cloud cover and frequent rain severely limit opportunities for optical satellite acquisitions. Synthetic aperture radar (SAR) sensors are well suited for rice mapping with their ability to acquire data regardless of cloud cover. Scholars have used multitemporal SAR data for rice identification and obtain good results ${ }^{[1-5]}$.

Taking advantage of SAR data in transplanting period, heading period and early harvest period, Shao Yun and other researchers ${ }^{[6]}$ measured distribution and acreage of rice in Zhaoqing, Guangdong Province, with the accuracy reaching 91\%. By means of multi time-phase Radarsat-1 image and neural network method, Chen and McNairn $^{[7]}$ obtained the acreage of rice with producer accuracy mounting to $96 \%$. Chen ${ }^{[8]}$ took advantage of Multi-polarization ASAR data to measure the rice acreage in Southern China with accuracy of $81 \%$. 
However these satisfactory classifications were obtainable using multi-temporal data and coinciding with the end of the growing season. Early season estimates of acreages are of significant interest for clients such as commodity brokers and marketing boards. In-season crop mapping and acreage estimates offer greater advantage.

Inoue and other researchers ${ }^{[9]}$ found that SAR data of X-band is applicable to monitor early growing season of crop, yet more challenging to achieve. New Germany radar satellite provides possibility in rice identification in early stage with regard to working frequency range, polarization mode (multi-polarization and quadpolarization) and revisit cycle (11 days).

This study aims to determine the best time to acquire SAR data for rice mapping during it's early season, determine the best rice growth stage to map rice, and develop the methods and procedure for rice mapping during early season. Thus in Xuwen, Guangdong study site, a time series of SAR data during early stage of early rice was obtained for this early season rice identification study. By comparing analysis of rice identification methods, the best period of rice identification during the early season was obtained, then the methods and procedures for rice mapping during the early season was developed.

\section{Site Description}

The Xuwen study site is located close to Leizhou City, Guangdong Province, China $\left(20.88^{\circ} \mathrm{N}, 110.06^{\circ} \mathrm{E}\right)$. Being in central part of Leizhou Peninsula and northern part of tropical monsoon zone, the site is featured with abundant heat and rainfall, along with a large number of thunderstorms in summer. It has a terrain with high northwest part and low southeast part. Most of rice is planted in flat area, while a little portion is planted in the valleys. Apart from rice, there are also upland crops such as sugarcane and vegetables, and commercial crops such as watermelon and pineapple in flat area. There are eucalyptus, orchard and upland crop such as sugarcane in brae area.

Rice in the area is double cropped (two harvests per year). Due to separate management pattern, famer's field management is relatively arbitrary with two main planting patterns - direct planting and transplanting. Meanwhile, the planting time span is quite long, so as to result in more obvious diversity in rice growing status during early age. In general cases, seeding period comes in mid-March, and the earlyApril is the transplanting stage. Tillering stage comes in the end of April and jointing stage comes in mid-May. June sees heading and flowering stage coming in the beginning of the month while mature period and harvest time in the end. Parcel of paddy field in study site is small with $100 \mathrm{~m}$ long and $30 \mathrm{~m}$ wide, and the weed echo on the ridge is quite obvious.

\section{Data acquisition}

Four TerraSAR-X acquisitions were programmed during early growth period in earlyrice of 2009. Data were collected in stripmap dual polarization mode with VV-VH 
polarizations with an incidence angle of $36.8^{\circ}$ in an ascending orbit. Nominal spatial resolution of the stripmap product is $6 \mathrm{~m}$. This resolution is well suited to the dimensions of the paddy fields typical of this study site. (1)The planting situation is complex in March 27 with great variance. Direct seeding paddy fields were planted and some early planted rice has emerged ; raising rice seedlings in transplanting fields was in operation with some fields in watering period awaiting for transplanting and some fields left unused without watering; some fields occupied by upland crops, such as hot pepper, would be transplanted with rice after harvest in the end of April. (2)In April 18, most of the rice in direct planting field emerged and was in seeding establishment period, and would be in tillering period in about a week; most of transplanting field began to be transplanted, and some fields after upland crop harvest were in watering operation, while a little portion of fields with upland crop were still in harvest operation. (3) In May 10, rice in most of transplanting fields were in jointing period as transplanting operation was finished before the end of April. The general stem length was about $60 \mathrm{~cm}$ and some rice has $45-50 \mathrm{~cm}$ stem length due to late transplanting operation, while some rice had only $35 \mathrm{~cm}$ stem length due to transplanting operation in the end of April after the harvest of upland crop. The growing variance was still obvious. (4) In June 1, most of paddy fields were in flowering period with remaining discrepancies with regard to stem length and leaf coverage due to different planting mode and time. However, the growing situation tended to be the same with stem length of $90-110 \mathrm{~cm}$.

Field surveys were conducted close to the satellite acquisition dates. The contents of investigation contained: (1) 41 ground control points were collected using a differential GPS with sub-meter accuracy. These ground control points were required to support ortho-correction of the imagery. (2)Several ground samples were collected with crops types, location information and photos. At last 219 ground samples were selected through visual interpretation of remote sensing image. There were 219 screening samples in total with remote sensing images. These samples were divided into two groups randomly. One was used to train class rules while the other was used to evaluate the effect of rice identification.

\section{Methods}

In this study, details of the image processing methods were illustrated as follows. First step is Data acquisition and Pre-processing, include image data acquisition, field data acquisition and data preprocessing. Then by contrast analysis of the different imagery of $\mathrm{VH}$ and $\mathrm{VV}$, the imagery with more obvious identification variance between rice and other major land cover types was selected. Next, the method and flow of classification was constructed for experiments of rice identification. At last the identification results of 4 temporally different images were obtained using above method and procedure, the best period of rice identification during early season was selected. 


\subsection{Data Acquisition and Preprocessing}

To suppress speckle, the imagery was filtered using a 3 by 3 Lee filter. TerraSAR-X data were then converted to $\beta^{0}(\mathrm{~dB})$. Ortho-correction was performed on both images using ground control points, DEM, and satellite ephemeris information. An RMS error under 1 pixel was achieved.

Backscatter is defined as radar cross section on unit area and could be obtained using formula (1), in which $\alpha_{d}$ represents the incident angle, $\mathrm{K}$ represents absolute calibration constant and A represents pixel brightness value $\beta^{0}$. In backscattering images, the value of $\sigma^{0}$ is reflected by tonal brightness. Then different SAR data could be compared with each other.

$$
\sigma^{0}=\frac{\left\langle A^{2}\right\rangle}{K} \sin \left(\alpha_{d}\right)
$$

\subsection{Data Analysis}

The paper acquired TerraSAR-X SM polarized images with dual polarization modes (VH and VV). The backscatter in dual-polarization mode contains more information for all land covers when comparing with single polarization mode. The interaction between radar wave and depolarization capacity of different polarization by land covers reflects attributive characters of different land cover types, such as dielectric properties, surface roughness, geometry form and direction, etc. Therefore, it is feasible for crop mapping using variation information of land covers in different polarization images. Calculate separately the difference imagery (Dvalue) of $\mathrm{VH}$ polarization and VV polarization backscattering coefficient for each TerraSAR-X data.

$$
\text { Dvalue }=V H-V V
$$

Based on the typical ground object samples, acquired throuth ground surveyed, the mean value and variance value of Dvalue for the dominant land cover types are provide in Table 1 and Figure 1. As shown in Table 1, we can see: (1)The variance between rice and other land covers becomes greater as time passed by. On March 27, there was minimum variance between rice mean value and construction land and upland due to the variance of rice planting time and mode. There was still a portion of paddy field without being planted or transplanted. The variance between different surface features in May 10 and June 1 was relatively more obvious (See figure 1a). (2) As time passed by, the variance value of rice gradually decreased, showing that the difference of rice growth brought about by planting mode and time gradually decreased, which was reflected in the figure as identification feature became more obvious and even (See figure 1b). 
Table 1. Mean value of D-value

\begin{tabular}{lcccc}
\hline Class & March-27 & April-18 & May-10 & June-1 \\
\hline Construction & -7.069 & -7.502 & -7.379 & -7.043 \\
Other & -3.369 & -4.440 & -6.173 & -6.107 \\
Paddy & -7.513 & -5.009 & -3.950 & -4.078 \\
Upland & -7.279 & -7.342 & -6.787 & -5.782 \\
Water & -1.746 & -2.480 & -2.696 & -2.076 \\
Woodland & -5.992 & -5.497 & -5.254 & -5.153 \\
\hline
\end{tabular}

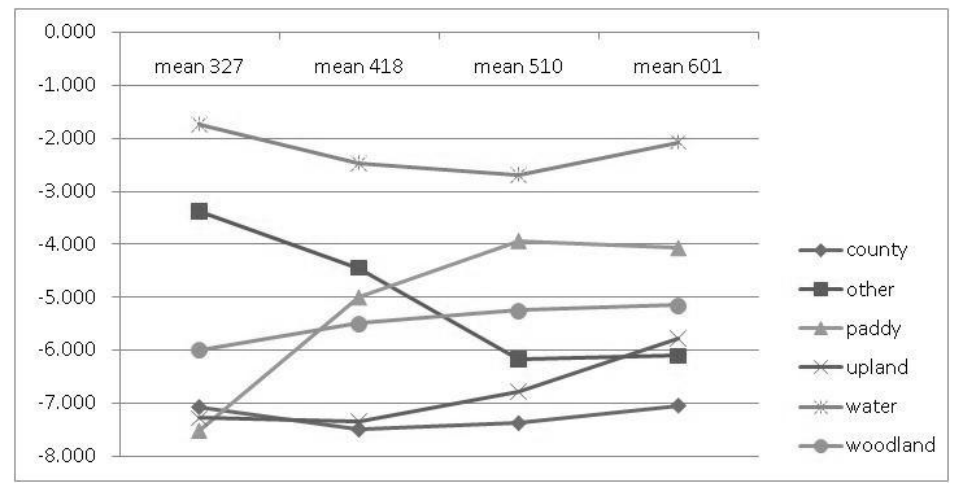

(a) Mean value

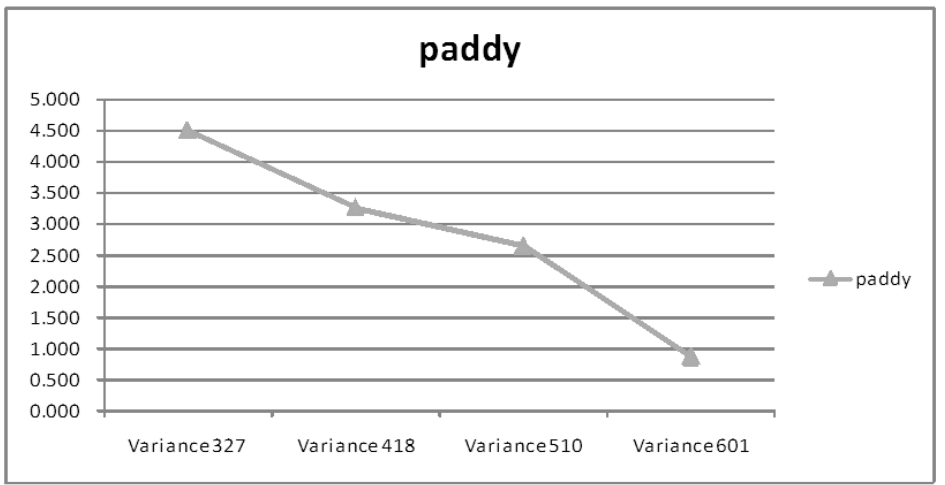

(b) Variance value

Fig. 1. The difference channel (VH-VV) temporal profile of typical ground objects

As analysis above, the backscatter on May 10 and June 1 showed more obvious features with regard to land cover separability and identification feature. Although the variance value of rice on May 10 was a little more than June 1, we can see from figure 2 that the variance still has obvious discrepancy with other land cover types, and the growth discrepancy brought by different rice planting mode was reflected by great variance. 


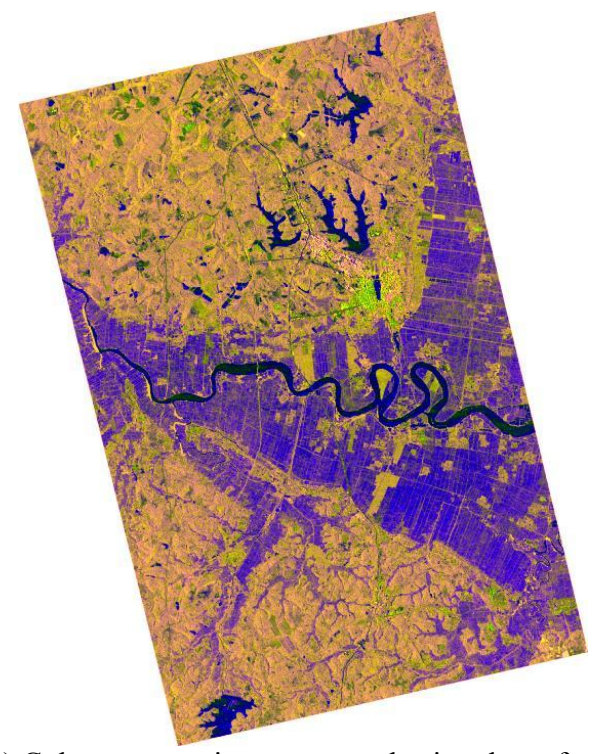

(a) Colour composite constructed using data of

$$
\text { May-10 }
$$

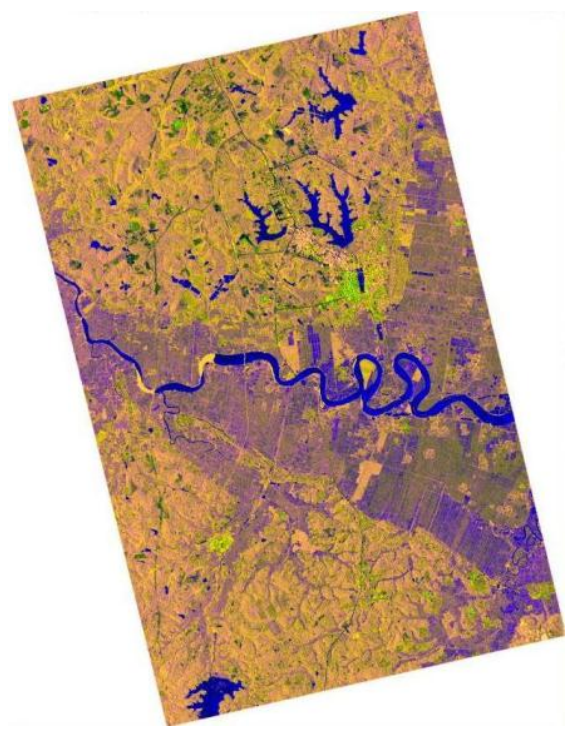

(b) Colour composite constructed using data of June-1

Fig. 2. Colour composite constructed using TerraSAR-X data where red represents VH, green represents VV, and blue represents the difference channel (VH-VV).

The visual inspection of the two date TerraSAR-X data of May 10 and June 1 indicate relatively obvious identification features among land cover types. Even though rice showed multi-identification features, there was obvious separability between rice and other land covers.

\subsection{Method and Flow of Rice Identification}

In order to further analyze the rice identification effect of 4 temporally different images, the paper conducted rice identification experiments and obtained classification results of 4 temporally different images based on methods of objectoriented classification and decision tree. Classification procedure (Figure 3 ) contains image preprocessing (radiometric calibration, ortho-correction, speckle filtering, backscatter extraction), image segmentation, training/testing sample preparation, supervised decision tree extraction, classification based DT and accuracy assessment. 


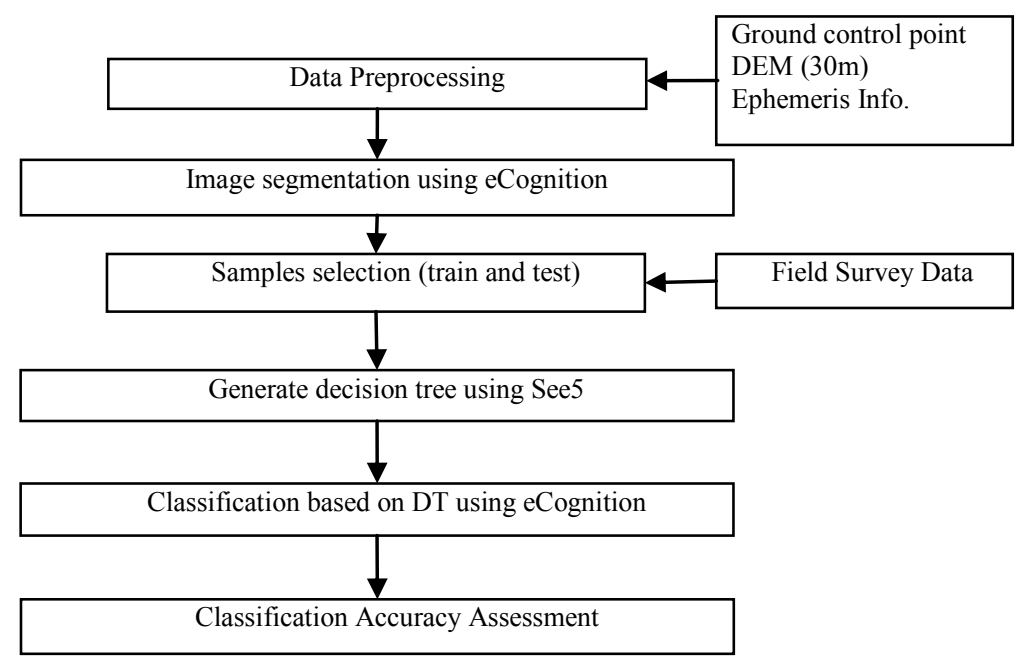

Fig. 3. Colour composite constructed using TerraSAR-X data where red represents VH, green represents $\mathrm{VV}$, and blue represents the difference channel (VH-VV).

First, Image segmentation was applied to the three-channel image in order to clearly demarcate parcels (objects) of homogeneity ${ }^{[10-11]}$. Segmentation was completed using eCognition ${ }^{\circledR}$ Definies Imaging ${ }^{[12]}$. Next, knowledge conclusion study and rule acquisition were separately realized using training sample information of every land cover type via See5 software, and relative statistics information of VH and VV's backscattering coefficient and D-value was taken as classification feature to create decision tree (DT). Then DT was defined in eCognition to obtain classification results. The classification accuracy was tested using independent test samples.

\section{Results and Analysis}

The entire study site was classified into 6 classes, including paddy rice, water, construction land, upland, woodland and other. Field surveyed sample data was settled according to this classification system (Table 2). We can see that the quantity distribution of every class sample was quite mean, in which construction land and water had little variation and little proportion in study site, while paddy and upland were major study objectives and had great variations as time passed by with more sample points. Sample set was divided into two parts randomly. As the quantities of training samples and validation sample were basically the same, the classification effect could be efficiently estimated. 
Table 2. Ground survey data composition of different land covers

\begin{tabular}{lccc}
\hline \multicolumn{1}{c}{ Classes } & Train Samples & Test Samples & $\begin{array}{c}\text { Total Number of } \\
\text { Fields Surveyed }\end{array}$ \\
\hline Paddy & 17 & 23 & 40 \\
Water & 18 & 15 & 33 \\
Construction land & 17 & 16 & 33 \\
Upland & 21 & 24 & 45 \\
Woodland & 17 & 16 & 33 \\
Other & 17 & 18 & 35 \\
Total Number & 107 & 112 & 219 \\
\hline
\end{tabular}

The 4 temporally images were processed and classified using the above method and procedures. Rice identification results were distinguished point by point using ground surveyed validation samples, and error matrix ${ }^{[13]}$ could be created (Table 3 ).

Table 3. Ground survey data composition of different land covers

\begin{tabular}{|c|c|c|c|c|c|c|c|}
\hline Class & Paddy & Water & $\begin{array}{l}\text { Construction } \\
\text { land }\end{array}$ & Upland & Woodland & Other & Overall \\
\hline \multicolumn{8}{|c|}{ User's Accuracy } \\
\hline $6-1$ & $100.0 \%$ & $93.8 \%$ & $92.9 \%$ & $80.0 \%$ & $81.3 \%$ & $77.8 \%$ & $87.4 \%$ \\
\hline $5-10$ & $91.7 \%$ & $93.3 \%$ & $93.3 \%$ & $76.0 \%$ & $76.5 \%$ & $87.5 \%$ & $85.7 \%$ \\
\hline $4-18$ & $81.8 \%$ & $100.0 \%$ & $70.6 \%$ & $65.4 \%$ & $66.7 \%$ & $76.5 \%$ & $75.7 \%$ \\
\hline $3-27$ & $84.2 \%$ & $100.0 \%$ & $65.0 \%$ & $59.3 \%$ & $60.0 \%$ & $58.8 \%$ & $69.6 \%$ \\
\hline \multicolumn{7}{|c|}{ Producer's Accuracy } & Kappa \\
\hline $6-1$ & $95.7 \%$ & $100.0 \%$ & $86.7 \%$ & $83.3 \%$ & $81.3 \%$ & $77.8 \%$ & 0.85 \\
\hline $5-10$ & $95.7 \%$ & $93.3 \%$ & $87.5 \%$ & $79.2 \%$ & $81.3 \%$ & $77.8 \%$ & 0.83 \\
\hline $4-18$ & $78.3 \%$ & $93.3 \%$ & $80.0 \%$ & $73.9 \%$ & $62.5 \%$ & $68.4 \%$ & 0.71 \\
\hline $3-27$ & $69.6 \%$ & $93.3 \%$ & $81.3 \%$ & $66.7 \%$ & $56.3 \%$ & $55.6 \%$ & 0.63 \\
\hline
\end{tabular}

We can see:

(1) The image of June 1 had the best classification result, most of the paddies was in the flowering period; The image of May 10 was the second best, in which most paddies were in the jointing period; March 27 and April 18 produced poorer results.

(2) Although the image of May 10 had lower accuracies than that of June 1, its overall accuracy, rice producer accuracy and user accuracy all achieved 85\%; as its acquisition was about 20 days ahead of June 1, it also could achieve effective 
identification of paddies in the study site in spite of a slightly lower classification accuracy (a decrease of 1.7\%).

From the above analysis, the image in June 1 had the best classification effect, in which period most of paddy was in flowering period; the image in May 10 took the second place, in which most paddy was in jointing period; March 27 and April 18 had inefficient effect. Although the image in May 10 had less efficient classification effect than that in June 1, its overall accuracy, rice producer accuracy and user accuracy all achieved 85\%; as its acquisition was about 20 days ahead of June 1, it also could achieve effective identification on paddy in the study site in spite of classification accuracy decreasing by $1.7 \%$. Considering the accuracy and timeliness, the image of May 10 is more suitable, and its accuracy estimation matrix is listed (Table 4).

Table 4. Xuwen study site classification result on May-10

\begin{tabular}{|c|c|c|c|c|c|c|c|c|}
\hline \multirow{2}{*}{$\begin{array}{c}\text { Fields } \\
\text { Surveyed }\end{array}$} & \multicolumn{7}{|c|}{ Classification Result } & \multirow{2}{*}{$\begin{array}{l}\text { Producer's } \\
\text { Accuracy }\end{array}$} \\
\hline & Paddy & Water & $\begin{array}{c}\begin{array}{c}\text { Construction } \\
\text { land }\end{array} \\
\end{array}$ & Upland & Woodland & Other & Sum & \\
\hline Paddy & 22 & 1 & 0 & 0 & 0 & 0 & 23 & $95.7 \%$ \\
\hline Water & 1 & 14 & 0 & 0 & 0 & 0 & 15 & $93.3 \%$ \\
\hline $\begin{array}{c}\text { Construction } \\
\text { land }\end{array}$ & 0 & 0 & 14 & 1 & 1 & 0 & 16 & $87.5 \%$ \\
\hline Upland & 1 & 0 & 1 & 19 & 2 & 1 & 24 & $79.2 \%$ \\
\hline Woodland & 0 & 0 & 0 & 2 & 13 & 1 & 16 & $81.3 \%$ \\
\hline Other & 0 & 0 & 0 & 3 & 1 & 14 & 18 & $77.8 \%$ \\
\hline Sum & 24 & 15 & 17 & 24 & 16 & 16 & 112 & --- \\
\hline $\begin{array}{c}\text { User's } \\
\text { Accuracy }\end{array}$ & $91.7 \%$ & $93.3 \%$ & $93.3 \%$ & $76.0 \%$ & $76.5 \%$ & $87.5 \%$ & $\begin{array}{c}\text { Overall } \\
\text { Accuracy }\end{array}$ & $85.7 \%$ \\
\hline
\end{tabular}

(1) Paddy, water and construction land have good identification effect as their producer accuracy and user accuracy both reached $85 \%$.

(2) Upland had less efficient producer accuracy and user accuracy, mixing up with woodland and other surface feature. The possible reason was upland crop in flat area, such as sugarcane, dispersed over many hills besides in flat areas, which might cause confusion with eucalyptus seedlings.

(3) Classification combination (Table 5) was conducted based on image classification. The surface features were combined into "paddy" and "other" with obtainable rice identification accuracy of $97.3 \%$. 
Table 5. Rice identification result on May-10

\begin{tabular}{rcccc}
\hline $\begin{array}{r}\text { Fields } \\
\text { Surveyed }\end{array}$ & Paddy & Other & Sum & $\begin{array}{c}\text { Producer's } \\
\text { Accuracy }\end{array}$ \\
\cline { 2 - 4 } Paddy & 22 & 1 & 23 & $95.7 \%$ \\
Other & 2 & 87 & 89 & $97.8 \%$ \\
Sum & 24 & 88 & 112 & --- \\
\hline $\begin{array}{r}\text { User's } \\
\text { Accuracy }\end{array}$ & $91.7 \%$ & $98.9 \%$ & $\begin{array}{r}\text { Overall } \\
\text { Accuracy }\end{array}$ & $97.3 \%$ \\
\hline
\end{tabular}

\section{Conclusions and Discussion}

(1) By using a decision tree and object-oriented classification method, TerraSAR-X data at the jointing period can achieve accurate rice identification in the early season with an accuracy of $97.3 \%$.

(2) The images at the seeding period and tillering period had poorer results. The accuracies were not sufficient to fulfil requirements for rice mapping. Both the images at the jointing period and flowering produced good classification accuracies, the flowering period having the best result but providing maps later in the season. Considering the accuracy and timeliness, imagery acquired at the jointing period is more suitable for rice identification during the early season for a nationwide operational rice monitoring system.

\section{Acknowledgment}

This study is supported by the project named High Resolution Multi-load Cooperative Agricultural Applied Technology Study which number is GF13/15311-003. We also thank Infoterra Asia Pacific(EADS-China) for the technical support.

\section{References}

1. Holecz F., Dwyer E., Monaco S., Schmid B., Frei U. An Operational Rice Field Mapping Tool Using Space Borne SAR Data. ERS-ENVISAT Symposium, 2000,Göteborg: October.

2. Toan T L, Ribbes F, Wang L-F, Floury, N. Kung-Hau Ding, Jin Au Kong, Fujita M., Kurosu T., CESBIO Toulouse. Rice Crop Mapping and Monitoring Using ERS-1 Data Based on Experiment and Modeling Results. IEEE Trans Geosci Remote Sensing, 1997,35(1), 41-56. 
3. Zhang P., Shen S., Li B., Wang X. Studies on rice polarization backscatter signatures and rice mapping methodology. Jiangsu Agricultural Sciences, 2006,(1), 148-152.

4. Guo L., Pei Z., Zhang S., et al. 2010. Rice identification using TerraSAR-X data, Proc. SPIE 8203, 82030J (2010), doi:10.1117/12.910396, Proc. Of SPIE Vol.8203 82030J-1- 82030J-7.

5. Pei Z., Zhang S., Guo L., et al. Rice identification and change detection using TerraSAR-X data, Canadian Journal of Remote Sensing, 2011,Vol. 37(1), 151-156.

6. Shao Y., Guo H., Fan X., Liu H. Studies on Rice Backscatter Signatures in Time Domain and Its Applications. Journal of Remote Sensing, 2001,5(5), 340-345.

7. Chen C., McNairn H. A Neural Network Integrated Approach for Rice Crop Monitoring. International Journal of Remote Sensing, 2006,27(7), 1367-1393.

8. Chen J., Lin H., Pei, Z. Application of ENVISAT ASAR Data in Mapping Rice Crop Growth in Southern China. Geosciences and Remote Sensing Letters, IEEE,2007, 4(3), 431-435.

9. Inoue Y., Kurosu T., Maeno H., Uratsuka S., Kozu T., Dabrowska-Zielinska K., Qi J. Season-long Daily Measurements of Multi-frequency (Ka, Ku, X, C, and L) and Fullpolarization Backscatter Signatures over Paddy Rice Field and Their Relationship with Biological Variables. Remote Sensing of Environment,2002, 81(2-3), 194-204.

10. Benz, U.C., Peter, H., Gregor, W. Multi-resolution Object-oriented Fuzzy Analysis of Remote Sensing Data for GIS-ready Information. ISPRS Journal of Photogrammetry \& Remote Sensing, 2004,Vol. 58, pp. 239-258.

11. Guo L., Pei Z., Wu Q., Liu Y., Zhao Z. Application of Method and Process of Objectoriented Land Use-cover Classification Using Remote Sensing Images. Transactions of the Chinese Society of Agricultural Engineering, 2010,26(7), 194-198.

12. Definiens Imaging. eCognition User Guide. $<$ http://www.definiensimaging.com/product.htm>, 2010.Definies Imaging $\mathrm{GmbH}$, Munich.

13. Foody, G M. Status of Land Cover Classification Accuracy Assessment. Remote Sensing of Environment, 2002,80, 185-121. 